\title{
3D MODELING OF A BAZAAR IN ANCIENT HARRAN CITY USING LASER SCANNING TECHNIQUE
}

\author{
H. I. SENOL ${ }^{1}$, S. ERDOGAN ${ }^{2}$, M. ONAL ${ }^{3}$, M. ULUKAVAK, A. MEMDUHOGLU ${ }^{5}$, S. MUTLU $^{6}$, F. B. ERNST ${ }^{7}$, M. YILMAZ $^{8}$ \\ ${ }^{1}$ Research Assistant, Harran University, Department of Geomatics Engineering, 63000 hsenol@ $@$ harran.edu.tr \\ ${ }^{2}$ Professor, Harran University, Department of Geomatics Engineering, 63000 serdogan@ harran.edu.tr \\ ${ }^{3}$ Professor, Harran University, Department of Archeology, 63000 monalbz@yahoo.com \\ ${ }^{4}$ Assistant Professor, Harran University, Department of Geomatics Engineering,63000 mulukavak@ harran.edu.tr \\ ${ }^{5}$ Research Assistant, Harran University, Department of Geomatics Engineering, 63000 akadirm@ harran.edu.tr \\ ${ }^{6}$ Specialist, Harran University, Department of Archeology, 63000 semihmutlu@ gmail.com \\ ${ }^{7}$ Assistant Professor, Harran University, Department of Geomatics Engineering, 63000 f.b.ernst@ harran.edu.tr \\ ${ }^{8}$ Assistant Professor, Harran University, Department of Geomatics Engineering,63000 yilmazmeh@ harran.edu.tr
}

KEY WORDS: Laser Scanning, 3D Modeling, Surveying

\begin{abstract}
:
Turkey is a rich country in historical monuments. In the district of Harran, Şanliurfa province, the work was done, an ancient city and many other ruins beside the world's first university can be found. Considering the climate and sensitive structure of the studied region 3D modeling is a suitable technique. By means of such works reconstruction, that can show us the former state of the region will be enabled at a later point of time. In case the historical site would be destroyed in any way, it will be useful for recording the work as a visual and digital resource. Then, when the work has to be restored, the data can be used as a base and realistic restoration projects could be carried out.
\end{abstract}

\section{INTRODUCTION}

Turkey is a rich country in historical monuments. In the district of Harran, Şanlıurfa province, the work was done, an ancient city and many other ruins beside the world's first university can be found. In this study, 3D archaeological survey of a bazaar (Turkish: Bedesten) area belonging to historical Harran site in Harran district of Şanliurfa province are explained. Stonex X300 laser scanner was used in the study.

Harran, was an important center of Mesopotamia, where moon, sun and planets were considered sacred. For this reason, astronomy is very advanced there. One of the three major schools of philosophy in the world was the Harran School. Typical Harran houses, mounds, castle walls, city walls and glowing stars in the night attract the attention of tourists.

Harran is located at an intersection of important trade routes connecting to the west from northern Mesopotamia. For this reason, Harran was one of the most important points of visit of Assyrian traders. This development of commercial culture has developed and culturally enriched Harran.

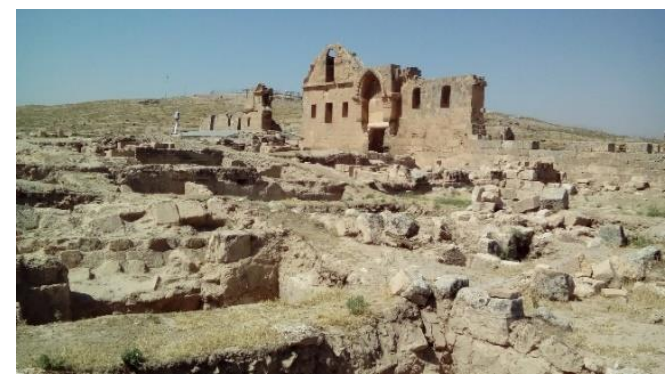

Figure 1. Study area

Excavation work in the Harran region continues (Figure 1). The bazaar located to the east of the Ulu Cami where this work was done can be described as follows;

"A wall of cut stone was found on the north parallel to the bath. Continuing on this wall are the shops that the opposite walls create. Because of the abundance of ceramic, glass and metal objects found at this site it was understood that this place was a ceramic, glass and spice shop. Excavations in this area produced especially handcrafts based on bronze and other metals like mortars and scales. These goods had a very important place in the trade of Harran city" (Önal, 2015). 


\section{TECHNIQUE AND METHODOLOGY}

"Laser scanning technique can be used as closed range data collection. In that way the device can collect geometrical data and the describe the geometrical object" (Assali, 2014).

In 3D scanning, the following steps are carried out during the process of receiving survey drawings;

- Identification of fixed reference points at the site to be studied

- Establishment of sketches belonging to the site and determination of a measurement plan

- Performing measurements at the study site using laser scanner

- Evaluation of data using a computer

- Making checks and getting results

- Modelling

\subsection{Identification of fixed reference points at the study site}

This stage is vital for measurements to be made with laser scanning. This is due to the fact that the point cloud is generated from laser data and that it is difficult to work in the point cloud. The more fixed points are be determined at the study site, the more accurate the results will be. Sensitivity may vary depending on the subject and region studied. In this work, pixel errors were tried to be kept in millimeter precision. Apart from this, the reference points should also consist of easily identifiable objects in the photographs (Figure 2, Figure 3). The more measurement is taken and the reference points are visible in this measurement, the more precise the operation will be. It will be more accurate if reference points have been identified when evaluating the data at a later stage.

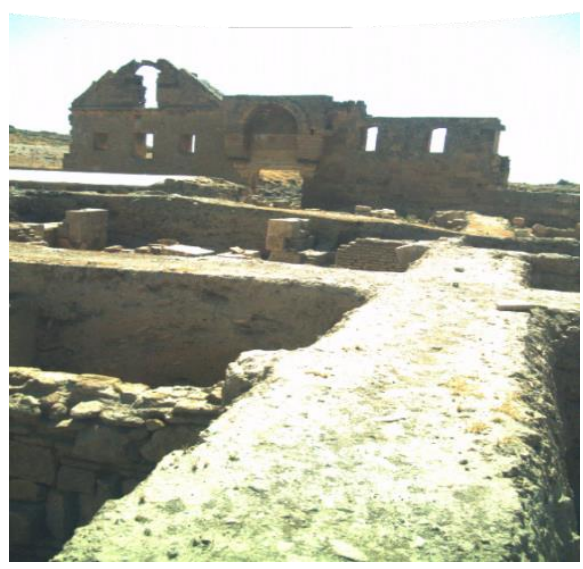

Figure 2. Study area

\subsection{Establishment of sketches of the study site and determination of measurement plan}

Sketches of the study site should be created manually or using digital device. If the work is outside, than a Google Earth map could be used too. It is important to know the environment, in which to work, and to make a careful progress of the work. Like we can get lost without a map in an unknown region, we may not be able to finish work at a site where we may lose data without having a sketch.

A measurement plan should be established by using the created charts. This measurement plan should be in a certain order and should be strictly followed during the next steps. At the same time, a careful selection of reference points will be facilitated the adjustment of the final point cloud that might be required due to unforeseen slides during the scanning process.

\subsection{Performing measurements at the study site with laser scanner}

The operating principle of 3D laser scanning devices is to produce a point cloud of the site by recording millions of points and taking many photographs by the device, which is looked at a certain angle to the spot to be observed. Laser scanner device provides much better quality and consistent results than photographic shoots. But people still continue to use the camera because laser scanners are expensive devices. Nevertheless, today, the use of these devices has increased considerably. These devices are used in various fields such as archaeology, criminology, construction, deformation measurement, and volume measurement. The Stonex X300 device that we use in our work was provided by Doğa Elektronik who also assisted in the measurement work.

It is very important to follow the plan when the measurement is made and to set up the device in a way that the reference points can be seen. The reason for this is that the noise that moving objects will create have to be dealt with when the point cloud will be processed. One of the most difficult parts of processing point clouds is the analysis and cleaning of noise.

\subsection{Evaluation of laser data}

Reconstructor Software published by Stonex Company was used to evaluate the data on graphical workstation. The reason for using this special software is its compatibility with the device. When the data are evaluated, previously determined fixed points will be marked as common points. In this regard, the model will consist only of a local co-ordinate system. The more fixed points are marked, the more consistent a pattern will be obtained. 


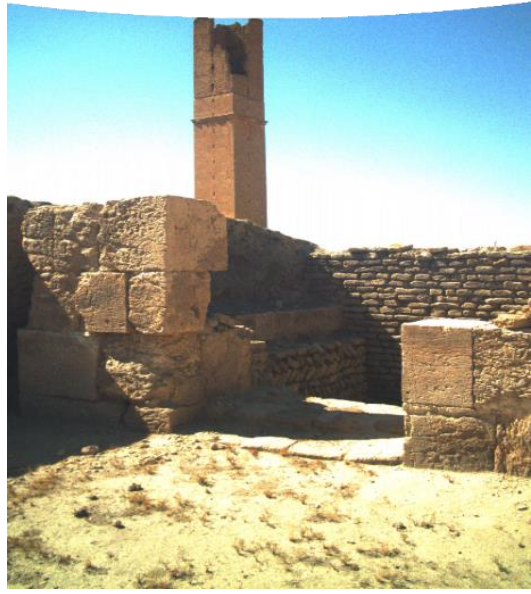

Figure 3. Study area

Another stage of the process is the removal of noise. Noise can be created by moving objects and other objects that are unnecessary for the measurement. For this reason, these objects must be removed from the image. However, due to the difficulty of this process, this operation must be done in a precise manner and should be limited as much as possible.

Afterwards, images of the device out of the processed point cloud will be produced and the program will order them in a systematic way.

\subsection{Making checks and getting results}

Error checks are made during the last step of the data processing. Errors are checked on the photographs at regular intervals. Correct any mistakes in possible errors. Unprocessed parts are removed from the point cloud. The resulting output is generated and the output is saved. This output can be exported and processed in other environments like CAD systems.

\subsection{Modelling}

It is important that the point cloud (Figure 4) is examined manually and correctly assembled during the modeling phase. Now, the reference points produced for this reason become important. Then, a model is created by superimposing the photographs on the merged point cloud (Figure 5).

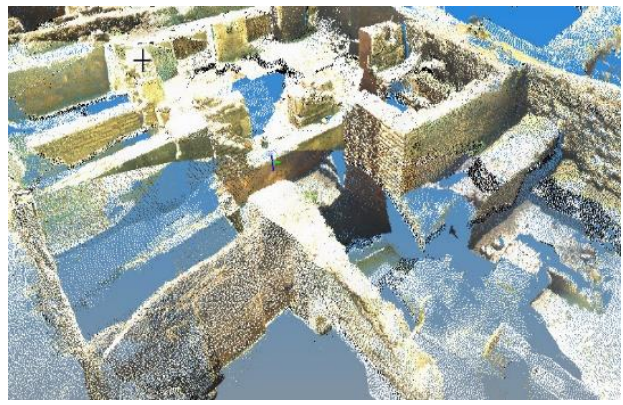

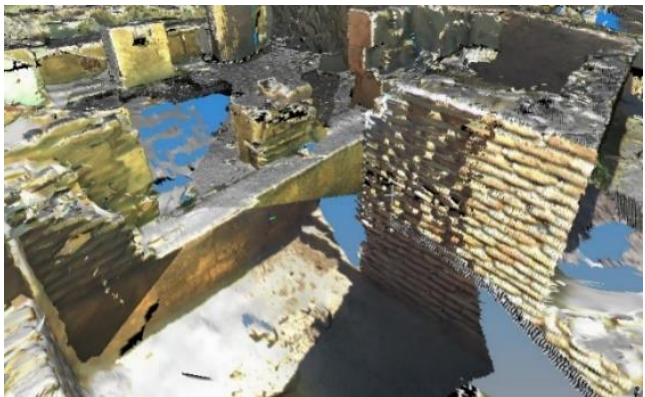

Figure 5. Point cloud after meshing

\section{RESULTS AND CONCLUSIONS}

Today, the requirements on data precision are very high. The more precise the data, the clearer and more legible outputs of measurements can be achieved. This is very important in the research of historical sites especially when fine handcraft is involved. With laser scanning, accurate and realistic models can be created and these models can be used in virtually any field. The results of this study can be found in Table 1 .

\begin{tabular}{|c|c|}
\hline \multicolumn{2}{|c|}{ Bundle adjustment report } \\
\hline Summary & Input parameters \\
\hline $\begin{array}{l}16 \text { scans have been finely } \\
\text { registered with bundle } \\
\text { adjustment }\end{array}$ & Max neighbors for each scan: 4 \\
\hline Num ICPs used: 35 & $\begin{array}{l}\text { ICP selection severity: Strict ICP } \\
\text { selection }\end{array}$ \\
\hline Average ICP error: 0.037081 & $\begin{array}{c}\text { ICP min search distance: } \\
0.500000 \mathrm{~m}\end{array}$ \\
\hline $\begin{array}{l}\text { Average registration error of } \\
\text { corresponding points: } 0.037921\end{array}$ & $\begin{array}{c}\text { ICP mac divergence point } \\
\text { normal: } 45^{\circ}\end{array}$ \\
\hline
\end{tabular}

Table 1 . Summary report after registration

During our next project, results of this study will be compared with data collected by unmanned aerial vehicles and the differences between aerial photography and terrestrial laser scanning will be researched. By this, advantages and disadvantages of both methods considering criteria like precision, accuracy and spatial characteristics of sites can be shown.

\section{REFERENCES}

Assali P., Grussenmeyer P., Villemin T., Pollet N., Viguier F., (2014) Surveying and modeling of rock discontinuities by terrestrial laser scanning and photogrammetry: Semi-automatic approaches for linear outcrop inspection Paper: 66, June 2014.

Önal M. (2015) Harran Örenyeri 2015 Y1lı Arkeolojik Çalışmaları, Şanlıurfa Kültür Sanat ve Turizm Dergisi, say1: 24, Ocak 2015.

Figure 4. Point cloud 